\title{
Notas com imagens fugidias: as armadilhas da temporalidade diaspórica
}

\author{
Notes on fugitive images: the traps of a diasporic \\ temporality
}

Prof ${ }^{a}$ Dra. Cíntia Guedes

Universidade Federal da Bahia

cintiaguedes7@gmail.com

Recebido em: 09/10/2020

Aceito em: 19/06/2021
Resumo

O artigo reúne uma série de três notas e um comentário que percorrem os desdobramentos iniciais da pesquisa Imagens fugidias: arquivos para um futuro preto. Em conversa com o trabalho de Luana Vitra, tento apontar os modos pelos quais gestos estéticos na arte contemporânea se comprometem com a composição de um imaginário disruptivo em relação ao regime de visualidade hegemônico e elaboram processos de imaginação radical com e para expressões artísticas que emanam desde perspectivas diaspóricas de grupos e pessoas racialmente subordinadas. Busco, assim, traçar algumas rotas pelas quais uma nova ecologia simbólica tem sido costurada e também vislumbrar possibilidades de elaboração crítica e além da crítica do que seriam temporalidades afrodiaspóricas nas artes.

Palavras-chave: Imagem, Afro diaspória, Arte contemporânea.

\section{Abstract:}

The text focus on a series of three notes and one commentary that go through the initial developments of the fugitive images research: archives for a black future, work in progress. In conversation with the Luana Vitra's work, I try to point out the ways in which aesthetic gestures in contemporary art are committed to the composition of a disruptive imaginary in relation to the regime of hegemonic visuality and elaborate the capacity for radical imagination with and for artistic expressions that emanate from diasporic perspectives of racially subordinated groups and people. Thus, I seek to trace some of the routes through which a new symbolic ecology has been sewn, and also to glimpse possibilities of critical approaches of what would be the afro diasporic temporalities in the arts.

Keywords: Image, Afro Diasporic, Contemporary Art. 


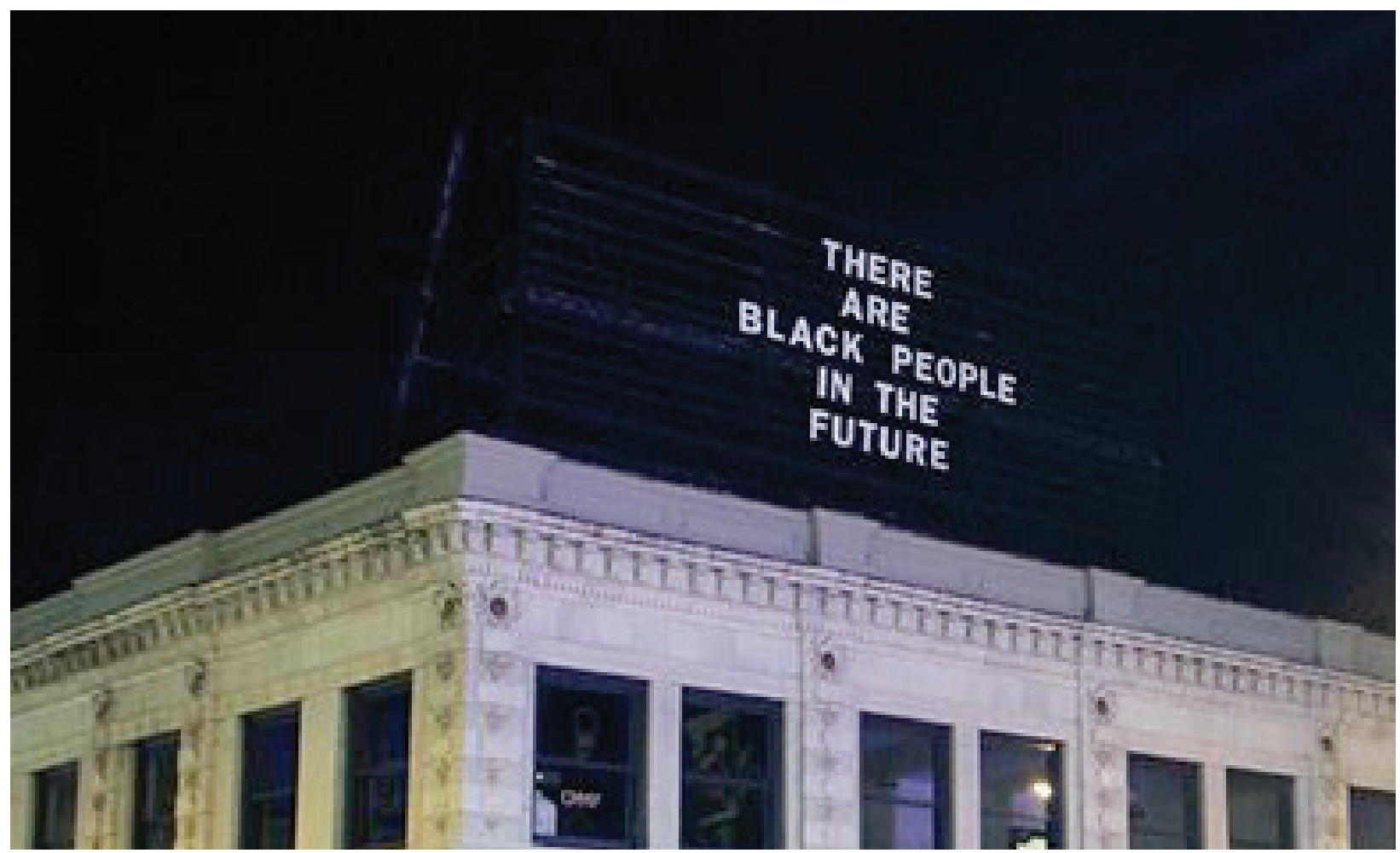

Imagem 1 - O último outdoor, Alisha Wormsley, 2018. Crédito: acervo de Jon Rubin

\section{Nota 1. Existem pessoas negras no futuro}

Em maio de 2018 a artista Alisha B. Wormsley ocupou com essa frase O Último Outdoor (The Last Billbord), espaço reservado a intervenções artísticas em Pittsburgh - Pensilvânia. Em pouco mais de 30 dias a instalação foi censurada pela empresa gestora do condomínio da construção onde fica o outdoor. O bairro no qual as palavras foram erguidas sofria um processo de intensa gentrificação e a ousadia especulativa de Alisha foi considerada ofensiva.

Essa "polêmica", assim como muitas outras que poderiam ser aqui citadas, nos informa sobre a evidente disputa que por toda parte pode ser percebida e que diz respeito ao futuro das vidas negras, as quais têm sido identificadas pelas marcas da negritude.

\section{Nota 2. Estudando o cativeiro}

A utilização do termo negritude, fabulado enquanto para fins de coalizão pelo martinicano Aimé Césaire em 1939 (em conversas com outros intelectuais ${ }^{1}$ ), sempre foi polissêmica, desdobrando-se enquanto proposição literária, artística, filosófica e, especialmente depois da segunda guerra, articulação política. Essa articulação funcionou como "uma operação de desintoxicação semântica e de constituição de um novo lugar de inteligibilidade da relação consigo, com os outros e com o mundo" (MUNANGA, 2019, p. 49). Não interessa aqui apontar uma origem do conceito, ou do movimento da negritude, mas sim traçar algumas das rotas pelas quais os usos e sentidos do termo desdobram-se no presente e alimentam um certo imaginário cativo da dominação colonial.

1 O termo aparece no jornal L’etudiant Noir (O estudante negro) fundado em 1934 por Aimé Césaire, pelo senegalês Léopold Sédar Senghor e por Léon-Gontran Damas, das Guianas Francesas. Destaco aqui o uso do termo no poema Diário de Retorno ao país Natal, publicado em sua primeira versão em 1939, como um dos principais marcos fundantes da ideia de negritude, mas o termo já havia aparecido outras vezes no mesmo jornal. 
Enquanto posição identitária, a negritude resulta da somatória de componentes históricos, linguísticos e psicológicos. Contudo, nunca se pretendeu definir através de tal termo as características biológicas ou culturais determinantes das pessoas portadoras das peles negras, uma vez que somos, em todos os aspectos, diversas. A negritude emerge, assim, como afirmação do valor das vidas negras e contra os processos de negação do pertencimento das mesmas ao estatuto do humano. Por isso, a categoria é mais bem descrita como a ligação entre os grupos humanos que "o olhar do mundo ocidental 'branco' reuniu sob o nome de negros" (MUNANGA, 2019, p. 17). Se há um solo comum de constituição da negritude, este assenta em um chamado de solidariedade entre aquelas/es que, na história, foram "vítimas das piores tentativas de desumanização" (MUNANGA, 2019).

Desde os primeiros momentos, o conceito aparecia como anseio desse grupo de escritores e intelectuais em mover-se em direção ao resgate dos valores culturais africanos, acachapados pelas invasões francesas, sendo já evidente que tal movimento de resgate consistia, no mais das vezes, em uma operação de desvio - uma articulação de forças de escape em relação às forças de assimilação colonialista e ocidentalizante. Estrategicamente, a negritude respondia (e responde) à hegemonia que emana da empresa colonial. Entretanto, já no primeiro momento de cunhagem, apontava-se os riscos de uma circunscrisão abstrata que achatava as múltiplas experiências vividas do negro, para ficar nos termos fanonianos (FANON, 2008). Por não contornar questões políticas específicas de determinados povos e territórios de África, e pela posterior articulação (mais especificamente na figura política de Léopold Senghor) em torno de uma cultura francófona, o movimento da negritude rendeu (e rende) debates e impasses entre intelectuais da diáspora .

Interessa-me sublinhar que a negritude tem sido majoritariamente articulada como chamado político dentro dos limites do pensamento humanista, ou seja, como expressão positiva de validação cultural, vontade de inclusão e legitimação, tudo em prol da manutenção material das vidas negras. Esse contorno humanista da negritude segue sendo categoria determinante para fins do fazer político, tendo reconhecidas implicações históricas, sociológicas e pedagógicas, as quais transbordam ainda pelo campo das subjetividades, uma vez que gera efeitos não apenas do ponto de vista material-político, mas também psicossocial.

Entretanto o humanismo, tal qual foi forjado por uma ideia antropocena de renascimento cultural entre os séculos XV e XVI, tem como processo constitutivo - e não como falha moral - a expropriação de corpos e territórios que denominou "outros". Seus desdobramentos alcançam as ciências humanas e suas teorias do sujeito, cujas heranças dizem respeito a uma capacidade inata de recentrar o problema do humano desde uma humanidade específica, cujo parâmetro é a Europa e sua história do progresso.

Este humano supostamente universal, ainda que tenha tido sua morte anunciada pela filosofia francesa pós-estruturalista branca, segue capaz de autoconstituir-se a partir de posições onto-epistemológicas de poder, pelas quais concomitantemente define as pessoas e territórios que seriam "outros". Trata-se do que Jota Mombaça (2020) elabora como processo de extorsão ontológica, movimento que tem sua materialidade expressa nas formas modulares pelas quais o modo de produção capitalista se perpetua e recria, ao longo da história, pelos territórios do mundo.

Para Mombaça, o mundo como o conhecemos, em suas formas anti-negritude e cisheteropatricarcal, precisa ser descrito como uma ficção naturalizada que nos oferece modos de conhecer a subjetividade e a produção artística e intelectual negra na forma de valor a ser roubado.

O que Mombaça está apontando são os modos pelos quais o capitalismo, ao longo da história e em seu modo contemporâneo de dominação fractal, tem efetiva capacidade de se atualizar infinitamente e capturar as formas de trabalho negro "cuja relação com o valor é sempre tensionada por dinâmicas de extração, objetificação e consumo do outro" (MOMBAÇA, 2017).

A partir de Mombaça, é possível compreender como a inclusão da vida negra nos limites do que chamamos de humanidade depende de que se opere a racialidade dentro e para um design do capital global, no qual a presença negra está encarcerada sob o signo de uma ausência, ou seja, fadada a operar com os registros do roubo e da violência, sendo levada a produzir, nas palavras da autora, formas de auto-objetificação positiva. 
A perda/roubo da memória, e a consequente "perda da imagem" (Beatriz Nascimento, 1989) enquanto efeito do sequestro colonial e de seus desdobramentos, é vetor determinante nos processos criativos que emanam dos grupos e pessoas racialmente subjugadas. Entretanto, quando assumida pela crítica hegemônica de arte, notadamente informada por uma ideia sumarizante de negritude, a retórica da perda encerra, majoritariamente, as aproximações às imagens da diáspora sob a insígnia da reparação.

O que pretendo aqui é ensaiar rotas para escapar das leitura míopes e pouco atentas à diversidade de operações estéticas elaboradas por poéticas que escapam entre temporalidades e linguagens. Ensaio outros modos de aproximação às imagens que, mesmo quando relacionam-se com a violência e a perda, excedem o clamor por reparação, denúncia ou inclusão. Ainda assim, ou justamente por isso, operam na emergência de uma imaginação engajada com o desmantelamento do que viria a ser o território onto-epistemológico de uma negritude confinada pelo (e como efeito do) humanismo.

Estou acenando aos deslocamentos em relação ao regime visual e narrativo que sustenta o entendimento do que vem a ser e de como chegamos a (re)conhecer-mo-nos enquanto negr_s. Perceber que, como negr_s, somos muitas outras coisas, e com todas elas, proponho que embarquemos em travessias que demandam do mundo outras condições de possibilidade e existência.

Para isso, tomo de partida o fato de que há, no trabalho das artistas da diáspora, assim como naquelas que engendram perspectivas indígenas, algo além de respostas às dinâmicas de (in)visibilidade, e que não pode ser lido sumariamente nem enquanto expressão de transcendência de um ser racializado, nem como a simples emanação de sua resistência confinada em um entendimento da negritude e do que se espera que essa categoria opere diante da crise ética contemporânea - a saber: o resgate do homem, a reparação de suas perdas, um novo marco civil, a edificação de novas bibliotecas de saberes e, consequentemente, a salvação de um mundo quebrado.

Estou mais bem interessada no que não se resolve na afirmação de uma negritude estatutária - regulada e definitiva-, e também naquilo que não se separa do trabalho especulativo que encontramos na afirmação de que existem pessoas negras no futuro.

Sublinho, portanto, a especulação com e sobre as imagens como condição para elaborar a sensibilidade que está além e abaixo das chaves da leitura crítica oferecida pelas lentes que buscam encontrar nas arquiteturas da memória o trabalho exclusivo da reparação da perda originária. Considero que, na tentativa de responder às dinâmicas da (in)visibilidade, essas abordagens sequer são suficientes para responder ao paradoxo da hipervisibilidade.

Afinal, não é propriamente a imagem de pessoas negras ou de seu passado que nos falta, essa é uma imagem constantemente replicada e excessivamente vinculada a uma gramática da dominação. A relação entre corpos negros e violência está posta, nos oferece imagens desde a primeira hora da manhã até o último jornal do dia, e elas não apenas cabem no mundo em que vivemos como conformam nosso imaginário, atravessam passado e presente e condicionam nossas projeções de futuro, tornam-se um horror aceitável e cotidiano. A violência racial é largamente percebida como experiência do 'senso comum'.

Não apenas nas imagens cotidianas, mas também nos estudos da história da arte encontramos um "repositório racial da memória" (EL-TAYEB apud IKI YOS, 2020), afinal, "como sabemos, para poder ser levada a cabo, a empresa colonial necessitou produzir um relato que a justificava” (MIÑOSO, 2018, p. 35). $\mathrm{Na}$ iconografia da representação dos corpos racializados, as imagens das pessoas negras e indígenas foram incorporadas nas paisagens, aparecendo como índices do passado e do primitivo nas pinturas dos chamados pintores viajantes. Assim, a disciplina colabora historicamente para uma organização visual hegemônica e promove o achatamento da pluralidade semântica e da potência afetiva das vidas retratadas.

O que excede a isso é vasto: gestos de criação artística e de vida que solicitam uma rigorosa investigação sobre como a especulação, o contra-feitiço e a transcriação acenam à produção de imagens outras, relacionadas aos processos de ancestralidade, vitalidade e cura, produzindo imagens que escapam às tradições do mimetismo realista que herdamos da moderna colonialidade. 
Quando avistamos em um outdoor a afirmação de que EXITEM PESSOAS NEGRAS NO FUTURO, ou quando assistimos bandeiras abertas em estádios de futebol, ou na frente de instituições de arte, perguntando ONDE ESTÃO OS NEGROS?, como o fez o coletivo Frente Três de Fevereiro para ocasião da exposição Histórias Afro-Atlânticas (2018), algo de abundante e além da denúncia, acontece e desconforta.

Sabemos onde estão as pessoas negras hoje, e sabemos onde se pretende que elas (não) estejam no futuro. Contudo, o que emana destas intervenções enquanto imagem pressupõe que ainda resta um trabalho a ser feito.

Nas formulações de Denise Ferreira da Silva (SILVA, 2019) sobre o fim mundo como o conhecemos e sobre uma poética negra feminista, aprendemos algo sobre uma certa sensibilidade que tanto presume quanto antecipa o que está além de tudo o que foi excessivamente dito e visto sobre a violência racial. $\mathrm{O}$ caráter fugidio das imagens é aquele que aciona imaginários ainda não previstos e solicita um tipo de trabalho que não pode ser imediatamente apropriado pelas forças do capital.

Se nenhum gesto no presente possui a capacidade de retornar ao passado e preenchê-lo com as imagens que nos faltam, o que as práticas em artes podem oferecer como arquivos da diáspora negra? Em que gestos podemos contornar o caráter performativo e especulativo dos arquivos, ou seja, sua porção de futuro? Como fabular um arquivo que compreenda as imagens que ainda não foram plenamente elaboradas, mas insistem em aparecer entre as vagas lembranças de nossas vitórias provisórias e a narração histórica e persistente de nossas derrotas?

\section{Nota 3. Cercando o cerco: memória como evocação libertadora}

"Todo historiador é um conversador e um sonhador" (2006, p.110 [1982]), afirma Beatriz Nascimento, historiadora alagoana que se dedicou a pensar os quilombos brasileiros. Insistindo na perspectiva que ampliava o marco temporal de existência desses espaços fugidios, Nascimento afirma que os quilombos não deixavam de existir após o evento da "abolição", apesar de assim argumentar a legislação da época². Para ela, as implicações sócio-culturais dos quilombos não poderiam ser plenamente compreendidas se descritas apenas enquanto eventos de resistência à opressão colonial.

Para Nascimento (2018), os quilombos são estruturas de emanação cultural que atravessam o tempo enquanto tecnologia ancestral de fuga. Um quilombo se ergue todas as vezes que uma comunidade afrodiaspórica recria sua relação com a terra, que aqui não é um dote ou propriedade, mas um elemento indispensável ao conjunto da vida humana, em seu significado semântico, simbólico e espiritual.

Para apreender os muitos modos pelos quais a noção de quilombo, tal qual fabulada por Nascimento, pode ofertar novos modos de aproximação às imagens que se relacionam tanto com o passado quanto com o futuro, nos parece fundamental promover um diálogo entre o quilombo de Nascimento e a metodologia de fabulação crítica operada pela historiadora Saidiya Hartman (2007). Ambas acordam que a experiência da perda da imagem e da memória tem sido elaborada como a pedra de toque da experiência partilhada pelas pessoas negras da diáspora. Uma baliza negativa que tornaria o trabalho da historiadora, da pesquisadora e da artista tanto impossível quanto infinito.

Hartman, entretanto, atenta para o fato de que a identidade das pessoas fugidias era definida tanto por aquilo do que estavam fugindo, quanto por aquilo que perseguiam. Os sonhos fugidios da diáspora, assim como as imagens fugidias, devem ser elaborados entre-temporalidades. A própria memória da artista, assim como a da historiadora, implicada intelectual e subjetivamente com aquilo que pesquisa e com as imagens que produz, opera com a perda em processos de transcriação (MARTINS, 2002), ou seja, na transformação da memória das imagens que toca.

2 A Constituição Federal de 1988 finalmente ampliou o entendimento legal de quilombo e quilombola. O quilombo foi então definido juridicamente como os grupos étnicos raciais remanescentes das comunidades dos quilombos, cuja definição passava a ter critérios de auto-atribuição, trajetória, dotação de relações territoriais específicas, ancestralidade negra presumida, além de estar relacionado com a resistência à opressão histórica sofrida. 


\section{Aproximação: as armadilhas do tempo nas imagens de Luana Vitra}

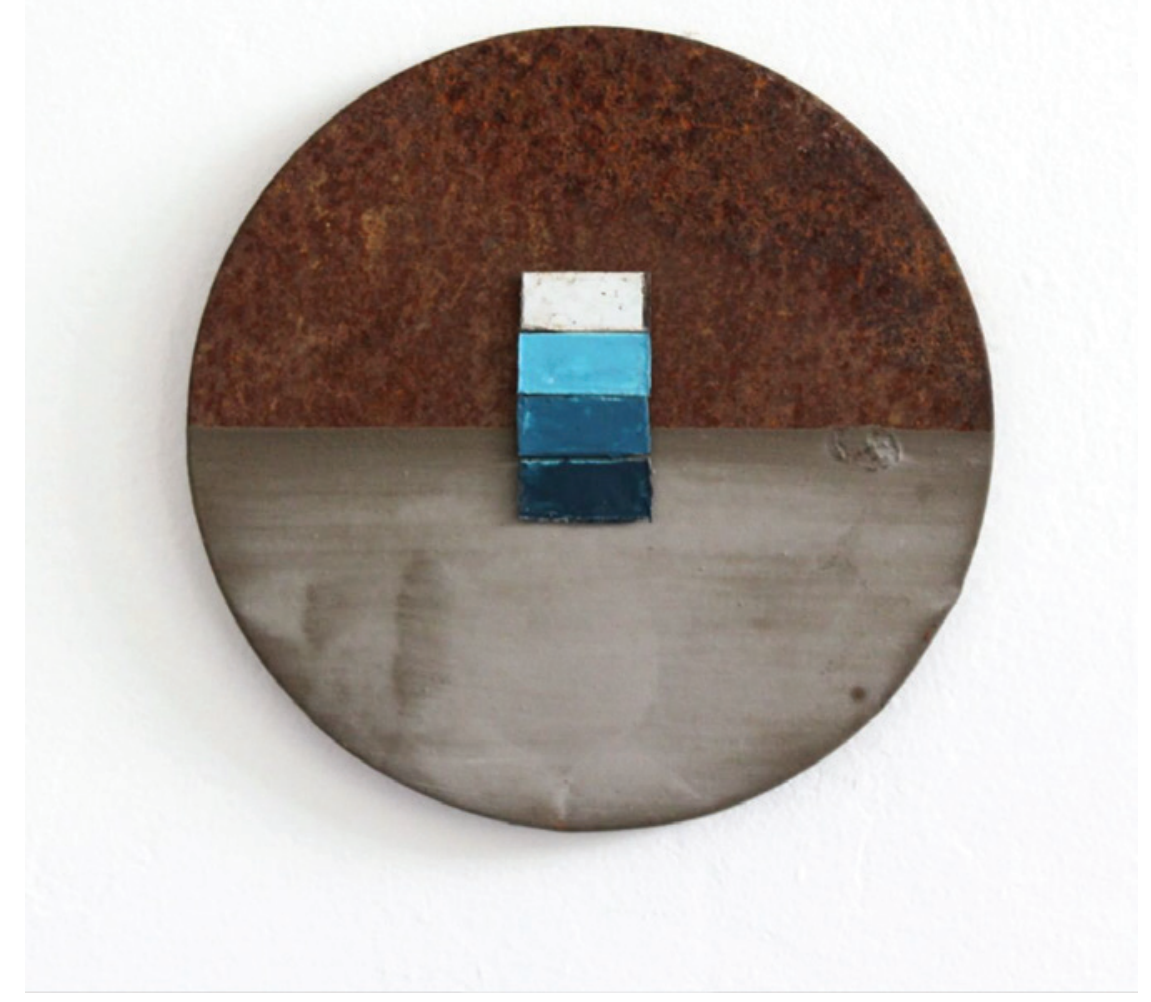

Imagem 2 - Objeto paisagem, Luana Vitra, 2018

Estava falando do tempo. É tão difícil pra mim acreditar no tempo. Algumas coisas vão embora. Passam. Algumas coisas ficam. Eu pensava que era minha rememória sabe. Algumas coisas você esquece. Outras coisas você não esquece nunca. Mas não é. Lugares, os lugares ainda estão lá. Se uma casa pega fogo, desaparece, mas o lugar - a imagem dela fica, e não só na minha rememória, mas lá fora, no mundo (MORRISON, 2011, p. 63).

E se, ao abordar o que o presente artigo convoca como imagens diaspórica e fugidias, aquelas que atravessam e desdobram as marcas da racialidade negra, tentássemos buscar não apenas as imagens que nos faltam, mas sobretudo a recomposição de uma temporalidade?

Para falar com as imagens que emanam das obras de Luana Vitra seria preciso saber dizer algo no 'presente do pretérito', alçar palavras para tocar as coisas que já 'foram' e continuam 'sendo'. Contudo, não estabelecemos na linguagem um tempo verbal para relatar travessias de desterro e retornos impossiveis. Em conversas com Luana, torna-se evidente a prática da artista, que parece trabalhar atenta ao momento em que as imagens acontecerem nas matérias. Por reconhecer essa prática, falamos aqui em armadilhar o tempo diaspórico.

É a professora, escritora e Rainha do Congado do Jatobá (MG) Leda Maria Martins que nos oferece as brechas para apreensão de uma estética da reminiscência, pelas quais argumento que se dão os movimentos de idas e vindas em um tempo espiralar que compõem as imagens de Luana, em gestos próximos ao que Martins conceituou como transcriação. 
Luana Vitra, que antes de se tornar artista visual já se sabia dançarina, apresenta em seus objetos e instalações o resultado de uma pesquisa que opera ativações da percepção sobre as qualidades performativas do tempo. Denota, assim, a habilidade de seu corpo - porque negro, rigorosamente atento, dançante e muitas outras coisas - em reconhecer os contornos sutis das matérias imersas nas voltas de um tempo expandido.

Assimilada do universo da construção civil, a lata de tinta é entendida aqui como objeto para transporte da paisagem. A terra, ou outro material transportado, é carregada de um espaço a outro e, desse modo, pode ser percebida como fragmento de uma paisagem que se desloca. Esse fragmento é levado para outra espacialidade e se realoca, promovendo alterações na paisagem onde foi derramado (VITRA, texto retirado do Instagram da artista, 2020).

Importante notar que Vitra não está pré-ocupada em produzir matéria de valor para efeito de representação de uma certa negritude nas artes. É porque se desobriga em responder às questões que emergem da dinâmica do extrativismo ontológico que recai sobre a produção artística e intelectual negra - sobre o trabalho negro (Mombaça, 2020) -, que a artista é capaz de (re)endereçar a questão do extrativismo da terra e do território, que por sua vez é o problema fundamental que incide e sobredetermina a ausência de valor da vida negra.

Neste movimento, faz não apenas uma denúncia, informa-nos também, e de modo sensível, que mesmo aquilo que desaparece no tempo da linearidade segue pleno de imagem. A artista se/nos oferece o trabalho de imaginá-las, e imaginar não se distancia do trabalho de rememorar. Contudo essa memória não está detida pela condição humana. Trata-se de uma re/inscrição libertadora dos corpos do mundo em um por-vir. O futuro deixa de ser apenas sumidouro e passa a ser espaço-tempo de co-criação, muito além do humano.

Aqui, a negritude funciona como lente e só pode ser acionada como chave de leitura do trabalho de Luana se tomada como uma posição que se constitui em relação às matérias, ao território, ao tempo e ainda às muitas outras posições, provisórias e instáveis, que o corpo artista atravessa. Trata-se de uma recusa em buscar a negritude apenas como resposta à inscrição do olhar da branquitude hegemônica.

Desta(s) posição(ões), mais do que um conteúdo da memória perdida ou um território identitário, emerge uma metodologia que se empenha em tangenciar os limites do des/conhecer. Não há definições prévias do aspecto que pregos, cimento, latas, arames, lixas, placas de ferro e madeira escolhidos para compor as obras devem ter. Ou seja, não há uma ideia prévia das formas figurativas que as matérias poderão chegar a compor nas obras, mas uma disponibilidade e um convite para estar em relação com os materiais, de "ser uma coisa entre as outras coisas do mundo" (FANON, 2008) e cooperar na formação de outras imagens.

Dada a origem residual, a fragilidade e a efemeridade dos materiais, um olhar apressado pode conferir ao trabalho a insígnia da precariedade como chave de leitura. Acredito, contudo, que embora Luana opere na ordem da reminiscência, não o faz como resposta reparadora ou elogio da escassez. Ela demanda do mundo as imagens que haviam se tornado impossíveis, e o faz no exercício de estar atenta à transmutação como condição perene daquilo que permanece e imprime no mundo a marca de uma existência.

Não é sobre padecer. A engenharia na justaposição dos elementos nos informa sobre a metamorfose e o serpentear do tempo. Cada um de seus objetos-paisagens é um fractal que contêm todas as imagens que aquela matéria já figurou e todas aquelas que talvez ela chegue a compor. É sobre escapar com e para outro tempo e sobre dedicar-se aos encontros, em relações que se dão para além do homem e seus desejos por semelhanças.

O primeiro gesto que Luana performa, usualmente no quintal da casa onde cresceu, é o de encontrar e escolher as matérias quando elas fazem um caminho de volta à condição de natureza. É precisamente na tentativa de retorno, despencadas do reino das coisas úteis, apresentando novas gramaturas, texturas, cores e suspensas em um certo estado de abandono, que Luana oferece às matérias o destino das imagens. Uma vez destituídas de seus usos fabris, elas são reintegradas ao mundo como fragmentos de horizonte. 
Retorno para a transcriação que Martins mobiliza para tratar do movimento performático do tempo nos rituais de congado e que aqui nos acompanha enquanto conceito, oferecendo as brechas para apreensão de uma estética da reminiscência em Vitra. Martins aponta que os movimentos "curvilíneos e prospectivos" da memória intencionam o resgate de matrizes, mas só podem realizar tal movida através da transcriação de novas posições de presenças para aquilo que assumimos como pretérito. Estando em diáspora, sabemos que também os apagamentos são incompletos. Imagens fugidias não operam respostas reparadoras, nem tratam apenas de buscar uma imagem para a origem das coisas inscritas (e perdidas) na temporalidade linear - do progresso, do apagamento -, mas sim embarcar no "movimento pendular entre lembrança e esquecimento" (MARTINS, 2002, p. 85).
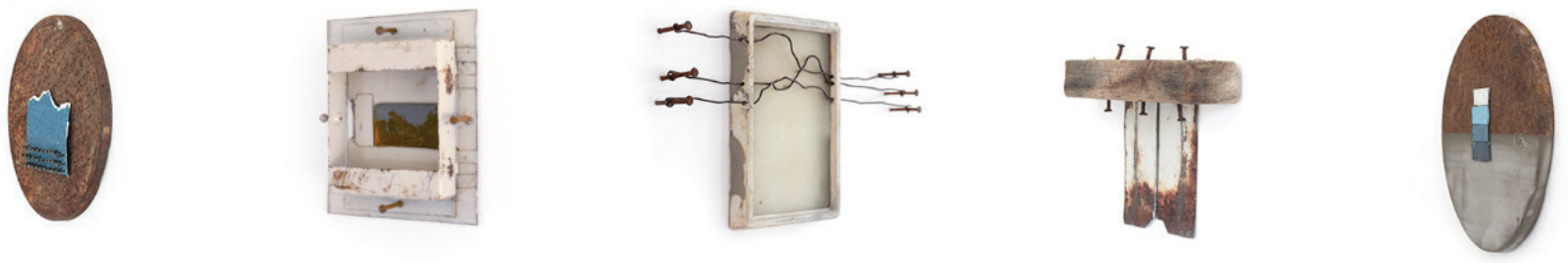

Imagem 3 - Objeto paisagem 2, Luana Vitra, 2018. Crédito: acervo da artista.

A imagem de Luana Vitra é movediça. Seus contornos se dão tanto naquilo do qual escapam - o tempo linear -, quanto naquilo que perseguem: possibilidades múltiplas de (re)implicação estética com o mundo, criação de temporalidades. São imagens, no sentido de Hartman, fugidias. A coloração da ferrugem ou as linhas montanhosas do ferro recortado compõem sempre novas imagens, que ao mesmo tempo nunca são inteiramente desconhecidas, pois "já estão realizadas tanto antes quanto depois do instante que a restitui", afinal, "nas espirais do tempo, tudo vai e tudo volta" (MARTINS, 2002, p.84).

\section{Referências}

HARTMAN, Saidiya. Lose Your Mother: A Journey Along the Atlantic Slave Route. 1 ed. Nova Iorque: Farrah, Straus and Giroux, 2007, p. 288.

FANON, Frantz. Peles negra, máscaras brancas. SILVEIRA, Renato (Trad.). 1 ed, Salvador: EDUFBA, 2008, p. 194.

MOMBAÇA, Jota. A coisa tá branca! Revista Buala, Lisboa, novembro 2017, p.11-12.

MOMBAÇA, Jota. A plantação cognitiva. MASP AfterAll. São Paulo: MASP, 2020, p.11-12.

NASCIMENTO, Maria Beatriz. Texto do filme Ôrí (1989). In: NASCIMENTO, Maria Beatriz. Beatriz Nascimento, Quilombola e Intelectual: Possibilidades nos dias da destruição. São Paulo: Editora Filhos da África, 2018.

NASCIMENTO, Maria Beatriz. Kilombo e memória comunitária: um estudo de caso. In: HATTZ, Alex (org.) Eu sou Atlântica: sobre a trajetória de vida de Beatriz Nascimento. Instituto Kuanza, São Paulo, 2006 [1982], p. 109-114.

MARTINS, Leda. Performances do tempo espiralar. In: RAVETTI, Graciela; ARBEX, Márcia (Orgs). Performances, exílio, fronteiras: errâncias territoriais e textuais. 1 Ed, Belo Horizonte: Departamento de Letras Romanas, Departamento de Letras UFMG, Poslit, 2002, p. 69 - 93.

MORRISON, Toni. Amada. SIQUEIRA, José Rubens (Trad.). 1 Ed, São Paulo: Companhia das Letras, 2017, p. 11-390.

MIÑOSO, Yuderkys Espinosa: Las Negras sempre estuviêmos desnudas. In: AYLLU, Colectivo (Org.). Devuélvanos el Oro: cosmovisiones perversas e acciones anticoloniales. 1 ed, Madrid: Matadero: 2018, p. 32 - 49.

MUNANGA, Kabengele. Negritude - usos e sentidos. 4a ed, Belo Horizonte: Autêntica Editora, 2019, 96 p.

SILVA, Denise Ferreira da. A dívida Impagável. São Paulo: 2019, 193 p. 